\title{
Genome-wide QTL mapping results for regional DXA body composition and bone mineral density traits in pigs
}

\author{
Sophie Rothammer ${ }^{1}$, Maren Bernau ${ }^{2}$, Prisca V. Kremer-Rücker ${ }^{2,3}$, Ivica Medugorac ${ }^{1}$, and \\ Armin M. Scholz ${ }^{2}$ \\ ${ }^{1}$ Chair of Animal Genetics and Husbandry, LMU Munich, 80539 Munich, Germany \\ ${ }^{2}$ Livestock Center of the Faculty of Veterinary Medicine, LMU Munich, \\ 85764 Oberschleissheim, Germany \\ ${ }^{3}$ University of Applied Sciences Weihenstephan-Triesdorf, 91746 Weidenbach, Germany \\ Correspondence to: Sophie Rothammer (s.rothammer@gen.vetmed.uni-muenchen.de)
}

Received: 12 December 2016 - Revised: 15 February 2017 - Accepted: 28 February 2017 - Published: 5 April 2017

\begin{abstract}
In a previous study, genome-wide mapping of quantitative trait loci (QTL) for five body composition traits, three bone mineral traits and live weight was performed using whole-body dual-energy X-ray absorptiometry (DXA) data. Since QTL for bone mineral traits were rare, the current study aimed to clarify whether the mapping results were influenced by the analysed body regions. Thus, the same material (551 pigs) and methods as in the whole-body QTL mapping study were used. However, for evaluation of the DXA scans, we manually defined two body regions: (i) from the last ribs to the pelvis (A) and (ii) including the pelvis and the hind limbs (P). Since live weight was not affected by the regional analysis, it was omitted from the QTL mapping design.

Our results show an overall high consistency of mapping results especially for body composition traits. Two thirds of the initial whole-body QTL are significant for both A and P. Possible causes for the still low number of bone mineral QTL and the lower consistency found for these traits are discussed. For body composition traits, the data presented here show high genome-wide Pearson correlations between mapping results that are based on DXA scans with the time-saving "whole-body standard setting" and mapping results for DXA data that were obtained by time-consuming manual definition of the regions of interest. However, our results also suggest that whole-body or regional DXA scans might generally be less suitable for mapping of bone mineral traits in pigs. An analysis of single reference bones could be more useful.
\end{abstract}

\section{Introduction}

In a previous study, whole-body dual-energy X-ray absorptiometry (DXA) data were used to perform a genome-wide mapping of quantitative trait loci (QTL) for the following nine traits: fat mass, fat percentage (Fat, FatPC), soft lean tissue mass, soft lean tissue percentage (Lean, LeanPC), live weight (Weight), soft tissue X-ray attenuation coefficient $(R)$, bone mineral content, bone mineral percentage (BMC, $\mathrm{BMCPC}$ ), and bone mineral density (BMD) (Rothammer et al., 2014). In total, 72 QTL were mapped and promising candidate genes (e.g. ZNF608) could be identified. From these 72 QTL, only seven QTL were associated with bone min- eral traits (two for BMC and BMD, another five for only $\mathrm{BMC}$ and none at all for BMCPC). Moreover, only two of these seven QTL were not simultaneously associated with body composition traits. Since it has been extensively shown that both weight and obesity correlate with bone metabolism in humans (reviewed by Cao, 2011; Zhao et al., 2008), associations of QTL with bone mineral traits could actually be indirectly caused by associations of these loci with body composition traits. The number of real bone mineral QTL would thus be reduced even more. However, this would be an unexpected result for two reasons: in humans, bone mineral traits were found to be strongly influenced by genetic aspects according to observations in families and twins (e.g. 
Pocock et al., 1987; Soroko et al., 1994; Hernandez-de Sosa et al., 2014). Furthermore, several QTL and candidate genes for bone mineral traits have already been identified in different species (e.g. Ames et al., 1999; Beamer et al., 2001; Xiao et al., 2012; Yang et al., 2012; Willing et al., 2003; Kaufman et al., 2008), including pigs (Laenoi et al., 2011, 2012; Rangkasenee et al., 2013). In pigs, there has been evidence for a genetic component in the multifactorial leg weakness syndrome, which is associated with osteochondrosis and bone fracture risk and thus with bone mineral traits (Laenoi et al., 2011, 2012; Rangkasenee et al., 2013). This syndrome affects animal welfare and profitableness in swine production (Fukawa and Kusuhara, 2001). The identification of QTL for bone mineral traits might therefore contribute to solving this serious problem (Laenoi et al., 2011, 2012; Rangkasenee et al., 2013). In contrast to our previous study (Rothammer et al., 2014), bone mineral measurements in humans by DXA scan are typically not conducted using a whole-body mode but restricted to distinct sites, e.g. the femoral neck or the lumbar spine (Wright et al., 2014). In this context, it has been shown that measured values can vary "substantially from site to site" (Arlot et al., 1997). This, in turn, raised the question of whether the whole-body mode that was used in the previous study had caused an underestimation of actual QTL numbers for bone mineral and possibly even body composition traits. In order to clarify this question, we repeated the mapping procedure for two manually defined body regions and compared the results among themselves and with the wholebody results of the previous study.

\section{Materials and methods}

Since the same material and methods as in the previous study (Rothammer et al., 2014) were used, the animal set comprised 551 pigs that were between 160 and 200 days old and that were a mixture of the following breeds in various proportions: Large Black, Pietrain, Duroc, Schwäbisch-Hällisch, Cerdo Iberico (Lampiño variety), European wild boar, and Hampshire. For all 551 animals, genotype data (Illumina's PorcineSNP60 Genotyping BeadChip) and DXA data were available. Based on these data, a genome-wide combined linkage disequilibrium and linkage analysis (Meuwissen et al., 2002) was conducted using 44611 20-SNP sliding windows. Variance component analyses were carried out at the midpoint of each sliding window using ASReml (Gilmour et al., 2009). The underlying mixed linear model included random QTL and polygenic and fixed effects of sex, housing, season and age. Finally, the likelihood ratio test statistic (LRT) was calculated using the logarithm of the likelihood estimated by ASReml for the model with (logLP) and without $(\log L 0)$ QTL effects (LRT $=-2(\log L 0-\log L \mathrm{P}))$. For more details on material and methods, see Rothammer et al. (2014).
In contrast to the previous study, DXA scans were not evaluated using the standard "whole-body" (WB) setting. Instead, two distinct regions were manually defined as shown in Fig. 1: (i) the region from the last ribs to the pelvis, called " $A$ " for "abdominal" in the following, and (ii) the region including the pelvis and the hind limbs, named "P" for "pelvic". As can be seen in Fig. 1, region A includes only the lumbar spine as the bony fraction and is thus comparable to bone mineral measurements in humans (according to the International Society for Clinical Densitometry (ISCD), the lumbar spine is an adequate and often used site for the diagnosis of osteoporosis or low bone mass in humans; Schousboe et al., 2013; Wright et al., 2014; El Maghraoui and Roux, 2008).

Moreover, since live weight is not affected by the regionof-interest analysis, this study concentrated on only eight traits for each body region (A and P): Fat, FatPC, Lean, LeanPC, R, BMC, BMCPC and BMD.

Mapping results for regions $\mathrm{A}, \mathrm{P}$ and $\mathrm{WB}$ were evaluated in two ways: (i) according to the (missing) overlap of significant QTL and (ii) using genome-wide Pearson correlations that were calculated based on the LRT values of all 44611 20-SNP sliding windows for each combination of DXA regions $(\mathrm{WB} \times \mathrm{A}, \mathrm{WB} \times \mathrm{P}$ and $\mathrm{A} \times \mathrm{P}$ ). Calculation of genomewide Pearson correlations was done for all eight traits separately as well as for three distinct combinations (bone mineral traits combined, body composition traits combined and all traits combined).

In addition, a linear regression analysis was performed to calculate the phenotypic relationship between whole-body DXA BMD and whole-body DXA fat mass using "Proc Reg" of SAS ${ }^{\circledR} 9.3$ software (CSAS Institute Inc., SAS Campus Drive, Cary, North Carolina 27513, USA).

\section{Results and discussion}

As can be seen in Fig. 2 and in the complete overview that is given in Fig. S1-8 in the Supplement, the mapping results (peak positions) were overall very similar for WB, A and $\mathrm{P}$ even though peak heights varied slightly. In the previous study (Rothammer et al. 2014) 72 QTL were detected in total. Eight of these QTL, however, were significant for only live weight. Thus, 64 QTL were detected for traits that were also investigated in the current study. From these, 59 QTL could be confirmed either by A (5), P (8) or both (46). Besides the QTL that had already been mapped for WB, additional QTL were identified for A (32), P (5) and the combination of both (8) (see Table S1 in the Supplement for unconfirmed WB QTL and newly identified A or P QTL). In general, these discrepancies are in most cases not due to the complete absence of former or the existence of new QTL but rather to the fact that the peaks of these QTL are close to the significance threshold (Bonferroni corrected $P$ value $<0.001)$. Thus, differences in peak size cause formerly suggestive QTL $(P<0.05)$ to become significant and 


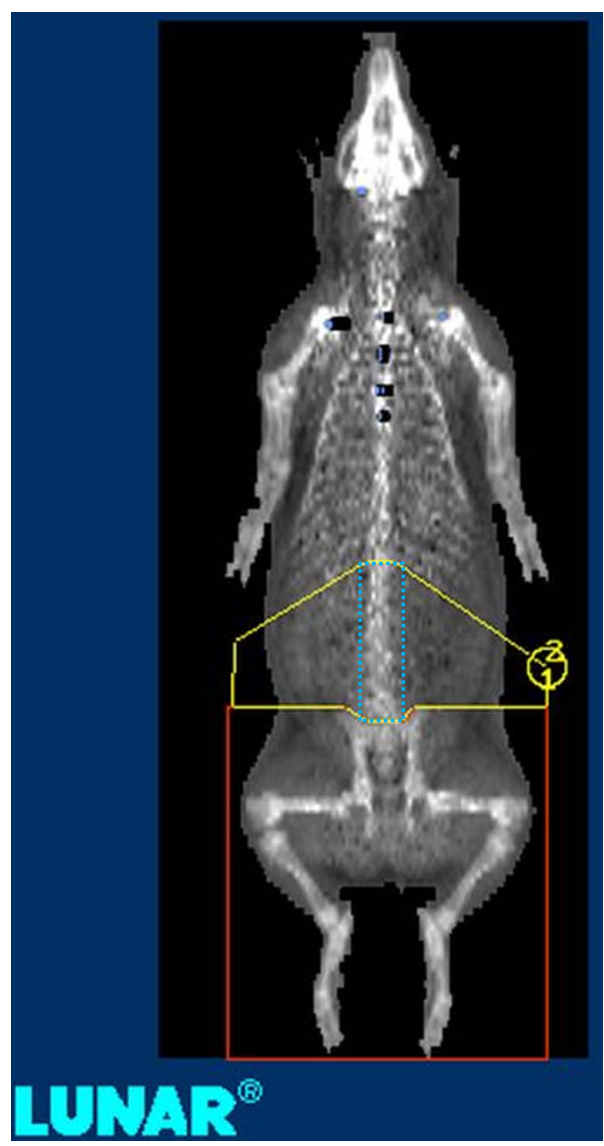

Figure 1. DXA scan showing the manually defined body regions. This screenshot of a DXA scan evaluation shows the manually defined body regions A (yellow) and $\mathrm{P}$ (red). While region A extends from the costal arch to the pelvis region, $\mathrm{P}$ includes the pelvis and the hind limbs. Moreover, region $\mathrm{A}_{\mathrm{B}}$, which was used for an additional scan and represents A restricted to the bony fraction only, is marked with a blue dotted box.

vice versa (Table S1). The overall high degree of accordance between the mapping results was also confirmed by genomewide Pearson correlations (Table 1, Fig. 3). Measured over all traits, the genome-wide Pearson correlation was 0.95 for WB and $\mathrm{P}$, and 0.89 for $\mathrm{WB}$ and $\mathrm{A}$. The genome-wide Pearson correlation between $\mathrm{A}$ and $\mathrm{P}$ was, although still high, somewhat lower (0.85). For all traits but FatPC, the same relations were found when traits were considered separately (Table 1). For FatPC, the genome-wide Pearson correlations between WB and A and between WB and P were almost identical $(0.979 ; 0.978)$. Generally, it can be assumed that the use of the (rather) time-saving WB DXA data provides as reliable and substantial results as the use of the time-consuming manually defined body regions.

However, of the 32 "new" QTL that were mapped for A, 12 (detected for the phenotypes Lean, Fat or R) did not show a suggestive peak in either the WB data or in P (Table S1). For these QTL, two explanations are possible: (i) they rep-
Table 1. Genome-wide Pearson correlations of QTL mapping results between DXA regions. This table shows the correlations between the genome-wide LRT values of the DXA regions "wholebody" (WB), "pelvic" (P) and "abdominal" (A) for all traits combined, bone mineral traits combined (bone), body composition traits combined (body) and single traits.

\begin{tabular}{lrrr}
\hline Pearson & WB $\times$ A & WB $\times \mathrm{P}$ & $\mathrm{A} \times \mathrm{P}$ \\
\hline All traits & 0.894 & 0.946 & 0.846 \\
Body & 0.922 & 0.971 & 0.896 \\
Bone & 0.664 & 0.838 & 0.571 \\
Fat & 0.906 & 0.969 & 0.885 \\
FatPC & 0.979 & 0.978 & 0.959 \\
Lean & 0.651 & 0.908 & 0.543 \\
LeanPC & 0.982 & 0.986 & 0.970 \\
R & 0.979 & 0.987 & 0.967 \\
BMC & 0.720 & 0.920 & 0.670 \\
BMCPC & 0.570 & 0.582 & 0.421 \\
BMD & 0.639 & 0.824 & 0.511 \\
\hline
\end{tabular}

resent QTL with only a local effect or (ii) the DXA scans and consequently the mapping results were biased by organs and/or intestinal contents that naturally occupy an enormous volume in region $\mathrm{A}$, thus increasing the number of false positives. Although (ii) cannot be ruled out without detailed studies of these QTL, the results of a literature study for all genes annotated to these 12 QTL supports assumption (i). For 2 of the 12 regions, only uncharacterised genes were annotated. The decision about a possible candidate status was thus hindered. However, in 7 of the 10 remaining regions, possible candidate genes could be identified: WBSCRI7 (International Mouse Phenotyping Consortium), SRSF7 (International Mouse Phenotyping Consortium), USP28 (Valero et al., 2001), NNMT (Trammell and Brenner, 2015), ZBED6 (Clark et al., 2015; Markljung et al., 2009), NMNAT2 (Hicks et al., 2012), ABHD6 (Thomas et al., 2013), PDHB (Sasaki et al., 2006; Serao et al., 2011) and PSMA2 (Sakamoto et al., 2009). These are listed in Table 2. These QTL that were found exclusively for region A might indeed represent QTL with exclusively or at least predominantly local effects. Thus, in cases where there is a special interest in a particular region of the body, manually analysed regions of interest might contribute additional knowledge about locally acting QTL.

In accordance with the results for WB bone mineral traits, no QTL was found for BMCPC for the manually defined regions $\mathrm{A}$ and $\mathrm{P}$. The number of QTL that were detected for $\mathrm{BMC}$ and BMD, however, differed markedly for regions A and P. While 11 QTL were found for region P, only one QTL was found for region A.

The QTL for region A was positioned on chromosome 13 and was verified three times as it was associated with bone mineral traits for not only region A (BMD; at 20010 946-20 621104 bp) but also region P (BMC, BMD; at 19832 456-21 $955312 \mathrm{bp}$ ) and WB (BMC; at 19850150 

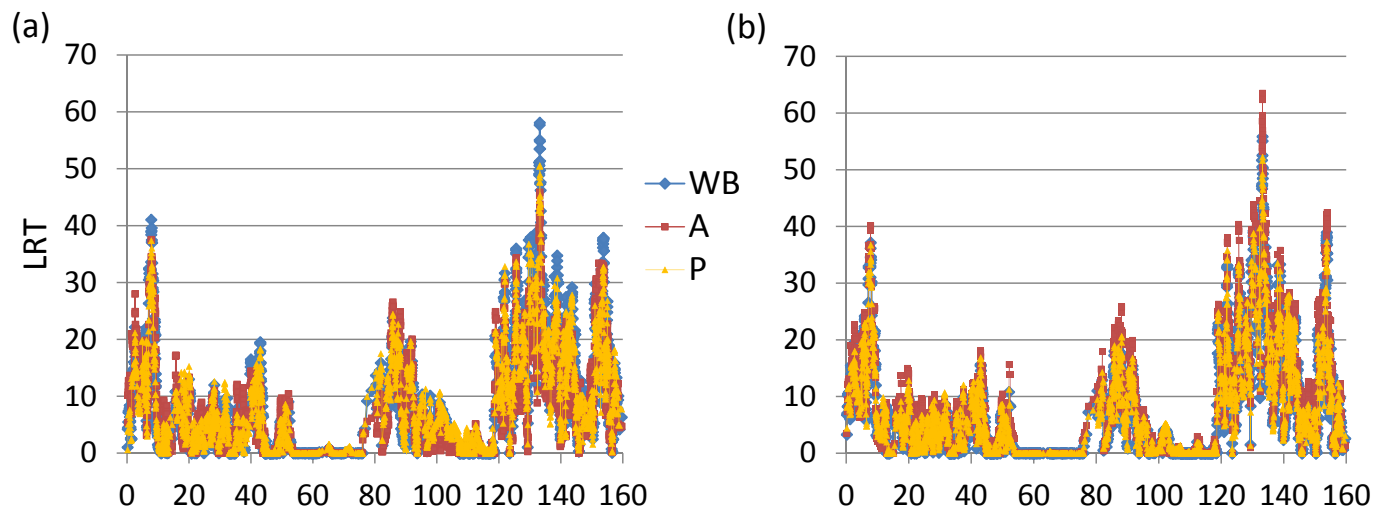

Figure 2. Comparison of local mapping results of whole-body data with manually defined regions. For chromosome 2 ( $x$ axis in Mb), this figure exemplarily shows the high consistency of the QTL mapping results for the three analysed regions (the whole body (WB), the abdominal (A) and the pelvic (P) region). Chromosome 2 was chosen for illustration as it harbours the genome-wide most significant LRT values for all three regions at position $133237232 \mathrm{bp}$. At this position, significant peaks (LRT >31.275) were detected for the traits Fat, FatPC, LeanPC, and R (and also Weight for WB) in all analysed regions. However, while Fat was the most significant trait in WB data, R was most significant for A and P. Thus, this figure shows the mapping results for both (a) Fat and (b) R (soft tissue X-ray attenuation coefficient).

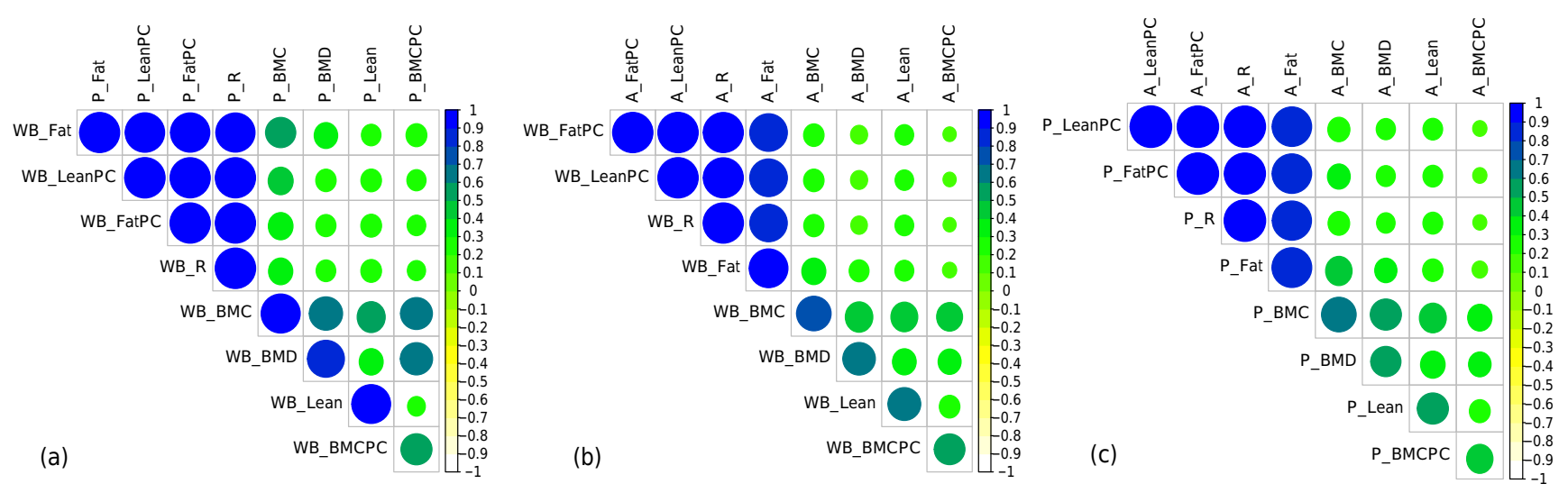

Figure 3. Graphical representations of the genome-wide Pearson correlation matrices for $\mathrm{WB} \times \mathrm{P}, \mathrm{WB} \times \mathrm{A}$ and $\mathrm{P} \times \mathrm{A}$. This visualisation reflects the correlations between different traits and DXA regions. Based on the diagonal, it is obvious that the correlation between WB and $\mathrm{P}$ is even higher than the correlation between WB and A, and between $\mathrm{P}$ and $\mathrm{A}$ (see also Table 1). Moreover, it is clearly visible that the body composition traits Fat, FatPC, LeanPC and R are highly correlated independent of the investigated region. Confidence matrices and plots were constructed using R (R Development Core Team, 2008) and the package corrplot (Wei, 2013). The order of the traits within the matrix differs according to the first principal components (parameter order set to "FPC"). Besides coloration, dot size also indicates the extent of correlation (dot size proportional to absolute value of correlation).

20339924 bp). In close proximity to the common region defined by these QTL (20010946-20339924 bp) lies the gene CMTM8 (20 414 847-20 $549120 \mathrm{bp})$. This gene acts as a candidate tumour suppressor gene (Both et al., 2014) and is associated with the EGFR (epidermal growth factor receptor) signalling pathway (Jin et al., 2005) which, in turn, is involved in the suppression of osteoblast differentiation and inhibition of osteoblastic transcription factor expression (Zhu et al., 2011). CMTM8 can thus be considered as a candidate gene for this QTL.

Concerning region P, all 11 QTL overlapped with QTL that had previously been identified for WB (Rothammer et al., 2014). Four of these WB QTL, however, had only been identified for body composition traits, not for bone mineral traits (Rothammer et al., 2014). To check the plausibility of these four QTL, a second literature study was conducted. By thorough screening of all positional candidate genes, we were able to identify possible bone mineral candidate gene(s)/hypotheses for each QTL:

The region defined by the QTL for BMC and Fat at chr3: $11090781-11719832 \mathrm{bp}$ is part of the critical region associated with Williams-Beuren syndrome (WBS) (Francke, 1999). This syndrome in humans is caused by heterozygous deletions of about $1.6 \mathrm{Mb}$, and one of the numerous symp- 
Table 2. Candidate genes for QTL detected for region A only.

\begin{tabular}{|c|c|c|c|c|}
\hline $\mathrm{Chr}$ & QTL position & Phenotype & GeneID & Description of association \\
\hline 3 & $14538518-15532954$ & Fat & WBSCR17 & $\begin{array}{l}\text { decreased lean body mass in mutant mice (International } \\
\text { Mouse Phenotyping Consortium) }\end{array}$ \\
\hline 3 & $107672432-108880944$ & Lean & SRSF7 & $\begin{array}{l}\text { decreased lean body mass in heterozygous mutant mice } \\
\text { (International Mouse Phenotyping Consortium) }\end{array}$ \\
\hline \multirow[t]{2}{*}{9} & $45927752-46989664$ & Lean & USP28 & $\begin{array}{l}\text { preferential expression in heart and muscle (Valero et } \\
\text { al., 2001) }\end{array}$ \\
\hline & & & $N N M T$ & correlates with adiposity (Trammell and Brenner, 2015) \\
\hline 9 & $70779512-71704720$ & Lean & ZBED6 & $\begin{array}{l}\text { regulates IGF2 expression and muscle growth in pigs } \\
\text { (Clark et al., 2015; Markljung et al., 2009) }\end{array}$ \\
\hline 9 & $136173120-137019760$ & Lean & NMNAT2 & $\begin{array}{l}\text { axonal growth } \rightarrow \text { missing innervation } \\
\rightarrow \text { reduction in total skeletal muscle mass (Hicks et al., } \\
2012 \text { ) }\end{array}$ \\
\hline \multirow[t]{2}{*}{13} & $43748912-44426072$ & Fat & ABHD6 & $\begin{array}{l}\text { selective knockdown protects mice from } \\
\text { high-fat-diet-induced obesity (Thomas et al., 2013) }\end{array}$ \\
\hline & & & $P D H B$ & $\begin{array}{l}\text { Candidate gene for intramuscular fat deposition in pigs } \\
\text { and cattle (Sasaki et al., 2006; Serao et al., 2011) }\end{array}$ \\
\hline 18 & $56485824-57128560$ & $\mathrm{R}$ & PSMA2 & $\begin{array}{l}\text { negative correlation with male BMI (Sakamoto et al., } \\
\text { 2009) }\end{array}$ \\
\hline
\end{tabular}

toms in about $15 \%$ of the cases is hypercalcemia (Cagle et al., 2004). Thus, at least one of the genes in this region must have an influence on blood calcium levels. In two severe cases of hypercalcemia, patients could successfully be treated by calcitonin, which increases the renal clearance of calcium and decreases the activity of osteoclasts, thereby increasing the amount of calcium that is bound in the bones (Cagle et al., 2004). Consequently, if certain a gene(s) in this region is (are) important for correct calcitonin release or function, an influence on bone mineral traits can be hypothesised.

For the QTL affecting BMC and Lean at chr6: 24770684 $26159346 \mathrm{bp}$, the genes EDC4 and NFATC3 may serve as candidate genes for bone mineral traits for the following reasons: according to Seto et al. (2015), the assembly of EDC4 and Dcp1a into processing bodies is critical for the translational regulation of IL-6, which plays a dual role in bone remodelling and bone tumours (Franchimont et al., 2005; Blanchard et al., 2009). Additionally, heterozygous EDC4 knockout mice showed a change in bone density, though it was not significant (Origins of bone and cartilage disease project, 2015). NFATC 3 regulates the expression of the NF- $\kappa \mathrm{B}$ ligand receptor activator in osteoblasts and is therefore involved in osteoclastogenesis (Lee et al., 2011).

The gene SNCA is a plausible candidate gene for the QTL associated with BMC at chr8: 138 766 256-139846368 bp as it was one of the top three genes correlated with bone mass in rat lines (Alam et al., 2010).
The QTL affecting BMD and Lean at chr9: 26965738 $28366584 \mathrm{bp}$ includes the gene FAT3, which was among 75 genes that were differentially expressed in human osteosarcoma cell lines (Luk et al., 2011). Thus, an involvement of FAT3 in bone homeostasis can at least be assumed.

None of these four P QTL were detected for bone mineral traits in WB data. However, there was also one bone mineral QTL that was mapped only in WB data and not in either A or P. This QTL affected BMC and Lean and was positioned at chr12: 41 715 472-44560156bp. Within this region, there are a number of cytokine genes (CCL1, CCL2, CCL8, CCL11). It is generally known that immune cells and cytokines are involved in regulating bone turnover (summarised in Nicolaidou et al., 2012). Of particular importance for bone remodelling is CCL2 (also MCP-1), which is associated, for example, with the recruitment of monocytes to areas of bone formation and bone resorption (reviewed in Yadav et al., 2010). Moreover, this QTL reached suggestive LRT values in both A (30.18) and P (26.46). Of the four QTL that were significant for only region $\mathrm{P}$, three showed suggestive LRT values for WB data. These facts and the promising results of the literature search thus affirm the basic ability of our methodology to map bone mineral traits.

Nevertheless, the mapping results and Pearson correlations for bone mineral traits, especially BMCPC and BMD, obviously show less accordance than those for body composition traits. Explanations for these findings can be (i) bone mineral traits are less influenced by genetics; (ii) for reliable bone 
mineral data, body regions must be even more restricted, e.g. to single bones; and (iii) the DXA method might not be perfectly suitable for measuring bone mineral traits in pigs in general.

Since bone mineral traits, osteoporosis and/or osteochondrosis have already been associated with distinct genomic regions, genes and/or variants in diverse species including humans, mice and pigs (Ames et al., 1999; Beamer et al., 2001; Willing et al., 2003; Xiao et al., 2012; Yang et al., 2012; Rangkasenee et al., 2013), explanation (i) seems to be rather unlikely. However, a plausible explanation might be the existence of numerous QTL with only small effects that could hinder their effective mapping (Bian and Holland, 2015; Heffner et al., 2009). To assess the probability of explanation (ii), we restricted region A to the bony fraction only $\left(A_{B}\right.$; see Fig. 1) and determined DXA values for 20 arbitrarily chosen animals. We then estimated phenotypic Pearson correlations of region $A$ and $A_{B}$ and found very high correlations of 0.91 for BMD and of 0.97 for BMC. Consequently, explanation (ii) is invalid for the lumbar region. Post-mortem QTL studies on bone mineral traits for ulna and radius, however, resulted in associated candidate genes like MMP3 (Laenoi et al., 2012) and KRT8 (Rangkasenee et al., 2013). Although the total number of QTL for bone mineral traits was also low here, scanning single bones might nonetheless be advantageous. At a first glance, explanation (iii) also seems implausible, especially when taking into account that DXA scans are still the gold standard for bone mineral trait measurements in humans. However, there are important differences between humans and pigs. To begin with, humans can be precisely positioned in a standardised way, while the same is much more complicated with anesthetised pigs. Since DXA reduces three-dimensional bodies to two-dimensional images (BMD is measured in $\mathrm{g} \mathrm{cm}^{-2}$, whereas volume is defined as $\left.\mathrm{g} \mathrm{cm}^{-3}\right)$, it is sensitive to positioning errors and also bone size (Carter et al., 1992; Vogl et al., 2011; El Maghraoui and Roux, 2008). Furthermore, osteoporosis in humans is not directly diagnosed by BMD but by the $\mathrm{T}$ score, which considers the mean BMD values and standard deviations of young adults of the same gender and ethnicity (El Maghraoui and Roux, 2008). It can thus be hypothesised that $\mathrm{T}$ scores might serve as more reliable phenotypes for QTL mapping than BMD values. However, since similar values for estimation of $\mathrm{T}$ scores based on BMD are missing for pigs, this hypothesis has not been verified yet. Based on the fact that the mechanical properties of bones are determined by BMD and bone microarchitecture, another shortcoming of the DXA method is its inability to differentiate between cortical and trabecular bone (Ulrich et al., 1999; Sornay-Rendu et al., 2006). Moreover, it has already been shown that increased body fat causes deviations in BMD measurements by DXA scans and, to a much lesser extent, also in quantitative computed tomography (QCT) (Yu et al., 2012). This finding is further supported by the observation of a medium phenotypic relationship between BMD and fat mass $\left(R^{2}=0.32 ; \mathrm{RMSE}=0.057 \mathrm{~g} \mathrm{~cm}^{-2}\right)$ in our own material. Whole-body BMD increases with growing body fat mass $\left(\mathrm{DXA} B M D=0.9978+5.397 \times 10^{-6} \times\right.$ DXA Fat). Since the breeding objectives of some breeds that were used in this study differ strongly with regard to fatness and leanness, measurements of bone mineral content and bone mineral density could indeed be biased and thus hinder effective QTL mapping. Consequently, it might be useful for mapping of bone mineral QTL if only crossbreeds between two breeds (e.g. Duroc $\times$ Pietrain as shown in Laenoi et al., 2011, 2012, and Rangkasenee et al., 2013) or at least similar breeds were used.

\section{Conclusion}

All in all, it can be stated that, especially for body composition traits, the results from a mapping with whole-body DXA data that were gathered using the time-saving standard setting were in high agreement with the results obtained for manually defined body regions of interest. Thus, timeconsuming manual DXA analyses can be restricted to studies in which local QTL are of particular interest. For certain bone mineral traits in pigs, however, it might be more useful to study reference bones by DXA or, for example, alternatively by QCT instead of using whole-body or regional DXA analysis.

Data availability. The original data are available upon request to the corresponding authors.

\section{The Supplement related to this article is available online at doi:10.5194/aab-60-51-2017-supplement.}

Author contributions. S. Rothammer designed and coordinated the mapping study, performed data analysis, interpreted data and drafted the manuscript. M. Bernau performed DXA analyses, blood sampling, veterinary control, and revised the manuscript. P. V. Kremer-Rücker performed DXA analyses, blood sampling, veterinary control, and revised the manuscript. I. Medugorac designed the mapping study, contributed analysis tools and revised the manuscript. A. M. Scholz designed and coordinated the study and critically revised the manuscript. All authors read and approved the final manuscript.

Competing interests. The authors declare that they have no conflict of interest.

Acknowledgements. The authors thank their colleagues for stimulating discussion, the stockmen for assistance with the DXA analysis, the laboratory staff for technical assistance and E. Kunz for proofreading. 
Edited by: S. Maak

Reviewed by: two anonymous referees

\section{References}

Alam, I., Carr, L. G., Liang, T., Liu, Y., Edenberg, H. J., Econs, M. J., and Turner, C. H.: Identification of genes influencing skeletal phenotypes in congenic P/NP rats, J. Bone Miner. Res., 25, 1314-1325, doi:10.1002/jbmr.8, 2010.

Ames, S. K., Ellis, K. J., Gunn, S. K., Copeland, K. C., and Abrams, S. A.: Vitamin D receptor gene Fok1 polymorphism predicts calcium absorption and bone mineral density in children, J. Bone Miner. Res., 14, 740-746, doi:10.1359/jbmr.1999.14.5.740, 1999.

Arlot, M. E., Sornay-Rendu, E., Garnero, P., Vey-Marty, B., and Delmas, P. D.: Apparent pre- and postmenopausal bone loss evaluated by DXA at different skeletal sites in women: the OFELY cohort, J. Bone Miner. Res., 12, 683-690, doi:10.1359/jbmr.1997.12.4.683, 1997.

Beamer, W. G., Shultz, K. L., Donahue, L. R., Churchill, G. A., Sen, S., Wergedal, J. R., Baylink, D. J., and Rosen, C. J.: Quantitative trait loci for femoral and lumbar vertebral bone mineral density in C57BL/6J and C3H/HeJ inbred strains of mice, J. Bone Miner. Res., 16, 1195-1206, doi:10.1359/jbmr.2001.16.7.1195, 2001.

Bian, Y. and Holland, J. B.: Ensemble Learning of QTL Models Improves Prediction of Complex Traits, G3 (Bethesda), 5, 2073 2084, doi:10.1534/g3.115.021121, 2015.

Blanchard, F., Duplomb, L., Baud'huin, M., and Brounais, B.: The dual role of IL-6-type cytokines on bone remodeling and bone tumors, Cytokine Growth F. R., 20, 19-28, doi:10.1016/j.cytogfr.2008.11.004, 2009.

Both, J., Krijgsman, O., Bras, J., Schaap, G. R., Baas, F., Y1stra, B., and Hulsebos, T. J.: Focal chromosomal copy number aberrations identify CMTM8 and GPR177 as new candidate driver genes in osteosarcoma, PloS one, 9, e115835, doi:10.1371/journal.pone.0115835, 2014.

Cagle, A. P., Waguespack, S. G., Buckingham, B. A., Shankar, R. R., and Dimeglio, L. A.: Severe infantile hypercalcemia associated with Williams syndrome successfully treated with intravenously administered pamidronate, Pediatrics, 114, 1091-1095, doi:10.1542/peds.2003-1146-L, 2004

Cao, J. J.: Effects of obesity on bone metabolism, J. Orthop. Surg. Res., 6, doi:10.1186/1749-799x-6-30, 2011.

Carter, D. R., Bouxsein, M. L., and Marcus, R.: New approaches for interpreting projected bone densitometry data, J. Bone Miner. Res., 7, 137-145, doi:10.1002/jbmr.5650070204, 1992.

Clark, D. L., Clark, D. I., Beever, J. E., and Dilger, A. C.: Increased prenatal IGF2 expression due to the porcine intron3-G3072A mutation may be responsible for increased muscle mass, J. Anim. Sci., 93, 2546-2558, doi:10.2527/jas.2014-8389, 2015.

El Maghraoui, A. and Roux, C.: DXA scanning in clinical practice, QJM, monthly journal of the Association of Physicians, 101, 605-617, doi:10.1093/qjmed/hcn022, 2008.

Franchimont, N., Wertz, S., and Malaise, M.: Interleukin-6: An osteotropic factor influencing bone formation?, Bone, 37, 601-606, doi:10.1016/j.bone.2005.06.002, 2005.

Francke, U.: Williams-Beuren syndrome: genes and mechanisms, Hum. Mol. Genet., 8, 1947-1954, 1999.
Fukawa, K. and Kusuhara, S.: The genetic and non-genetic aspects of leg weakness and osteochondrosis in pigs - Review, Asian Austral. J. Anim., 14, 114-122, 2001.

Gilmour, A. R., Gogel, B. J., Cullis, B. R., and Thompson, R.: ASReml User Guide (Release 3.0), available at: http:// vsni.de/downloads/asreml/release3/UserGuide.pdf (last access: 27 February 2014), 2009.

Heffner, E. L., Sorrells, M. E., and Jannink, J. L.: Genomic Selection for Crop Improvement, Crop. Sci., 49, 1-12, doi:10.2135/cropsci2008.08.0512, 2009.

Hernandez-de Sosa, N., Athanasiadis, G., Malouf, J., Laiz, A., Marin, A., Herrera, S., Farrerons, J., Soria, J. M., and Casademont, J.: Heritability of bone mineral density in a multivariate family-based study, Calcified Tissue Int., 94, 590-596, doi:10.1007/s00223-014-9852-9, 2014.

Hicks, A. N., Lorenzetti, D., Gilley, J., Lu, B., Andersson, K. E., Miligan, C., Overbeek, P. A., Oppenheim, R., and Bishop, C. E.: Nicotinamide mononucleotide adenylyltransferase 2 (Nmnat2) regulates axon integrity in the mouse embryo, PloS one, 7, e47869, doi:10.1371/journal.pone.0047869, 2012.

International Mouse Phenotyping Consortium: available at: http:// www.mousephenotype.org, last access: 25 November 2016.

Jin, C., Ding, P., Wang, Y., and Ma, D.: Regulation of EGF receptor signaling by the MARVEL domain-containing protein CKLFSF8, FEBS letters, 579, 6375-6382, doi:10.1016/j.febslet.2005.10.021, 2005.

Kaufman, J. M., Ostertag, A., Saint-Pierre, A., Cohen-Solal, M., Boland, A., Van Pottelbergh, I., Toye, K., de Vernejoul, M. C., and Martinez, M.: Genome-wide linkage screen of bone mineral density (BMD) in European pedigrees ascertained through a male relative with low BMD values: evidence for quantitative trait loci on 17q21-23, 11q12-13, 13q12-14, and 22q11, J. Clin. Endocr. Metab., 93, 3755-3762, doi:10.1210/jc.2008-0678, 2008.

Laenoi, W., Uddin, M. J., Cinar, M. U., Grosse-Brinkhaus, C., Tesfaye, D., Jonas, E., Scholz, A. M., Tholen, E., Looft, C., Wimmers, K., Phatsara, C., Juengst, H., Sauerwein, H., Mielenz, M., and Schellander, K.: Quantitative trait loci analysis for leg weakness-related traits in a Duroc x Pietrain crossbred population, Genet. Sel. Evol., 43, 1-7, doi:10.1186/1297-9686-43-13, 2011.

Laenoi, W., Rangkasenee, N., Uddin, M. J., Cinar, M. U., Phatsara, C., Tesfaye, D., Scholz, A. M., Tholen, E., Looft, C., Mielenz, M., Sauerwein, H., Wimmers, K., and Schellander, K.: Association and expression study of MMP3, TGFbeta1 and COL10A1 as candidate genes for leg weakness-related traits in pigs, Mol. Biol. Rep., 39, 3893-3901, doi:10.1007/s11033-011-1168-5, 2012.

Lee, H. L., Bae, O. Y., Baek, K. H., Kwon, A., Hwang, H. R., Qadir, A. S., Park, H. J., Woo, K. M., Ryoo, H. M., and Baek, J. H.: High extracellular calcium-induced NFATc3 regulates the expression of receptor activator of NF-kappaB ligand in osteoblasts, Bone, 49, 242-249, doi:10.1016/j.bone.2011.04.006, 2011.

Luk, F., Yu, Y., Dong, H. T., Walsh, W. R., and Yang, J. L.: New gene groups associated with dissimilar osteoblastic differentiation are linked to osteosarcomagenesis, Cancer genomics \& proteomics, 8, 65-75, 2011.

Markljung, E., Jiang, L., Jaffe, J. D., Mikkelsen, T. S., Wallerman, O., Larhammar, M., Zhang, X., Wang, L., Saenz-Vash, V., Gnirke, A., Lindroth, A. M., Barres, R., Yan, J., Stromberg, S., 
De, S., Ponten, F., Lander, E. S., Carr, S. A., Zierath, J. R., Kullander, K., Wadelius, C., Lindblad-Toh, K., Andersson, G., Hjalm, G., and Andersson, L.: ZBED6, a novel transcription factor derived from a domesticated DNA transposon regulates IGF2 expression and muscle growth, PLoS Biol., 7, e1000256, doi:10.1371/journal.pbio.1000256, 2009.

Meuwissen, T. H. E., Karlsen, A., Lien, S., Olsaker, I., and Goddard, M. E.: Fine mapping of a quantitative trait locus for twinning rate using combined linkage and linkage disequilibrium mapping, Genetics, 161, 373-379, 2002.

Nicolaidou, V., Wong, M. M., Redpath, A. N., Ersek, A., Baban, D. F., Williams, L. M., Cope, A. P., and Horwood, N. J.: Monocytes induce STAT3 activation in human mesenchymal stem cells to promote osteoblast formation, PloS one, 7, e39871, doi:10.1371/journal.pone.0039871, 2012.

Origins of bone and cartilage disease project: Gene of the month June 2015: Edc4: available at: http://www.boneandcartilage. com/GOTMarchive.html (last access: 25 November 2016), 2015.

Pocock, N. A., Eisman, J. A., Hopper, J. L., Yeates, M. G., Sambrook, P. N., and Eberl, S.: Genetic determinants of bone mass in adults. A twin study, J. Clin. Invest., 80, 706-710, doi:10.1172/JCI113125, 1987.

R: A Language and Environment for Statistical Computing: available at: http://www.R-project.org (last access: 13 February 2017), 2008.

Rangkasenee, N., Murani, E., Brunner, R., Schellander, K., Cinar, M. U., Scholz, A. M., Luther, H., Hofer, A., Ponsuksili, S., and Wimmers, K.: KRT8, FAF1 and PTH1R gene polymorphisms are associated with leg weakness traits in pigs, Mol. Biol. Rep., 40, 2859-2866, doi:10.1007/s11033-012-2301-9, 2013.

Rothammer, S., Kremer, P. V., Bernau, M., Fernandez-Figares, I., Pfister-Schar, J., Medugorac, I., and Scholz, A. M.: Genomewide QTL mapping of nine body composition and bone mineral density traits in pigs, Genet. Sel. Evol., 46, 1-11, doi:10.1186/s12711-014-0068-2, 2014.

Sakamoto, K., Sato, Y., Shinka, T., Sei, M., Nomura, I., Umeno, M., Ewis, A. A., and Nakahori, Y.: Proteasome subunits mRNA expressions correlate with male BMI: implications for a role in obesity, Obesity (Silver Spring), 17, 1044-1049, doi:10.1038/oby.2008.612, 2009.

Sasaki, Y., Nagai, K., Nagata, Y., Doronbekov, K., Nishimura, S., Yoshioka, S., Fujita, T., Shiga, K., Miyake, T., Taniguchi, Y., and Yamada, T.: Exploration of genes showing intramuscular fat deposition-associated expression changes in musculus longissimus muscle, Anim. Genet., 37, 40-46, doi:10.1111/j.13652052.2005.01380.x, 2006.

Schousboe, J. T., Shepherd, J. A., Bilezikian, J. P., and Baim, S.: Executive Summary of the 2013 International Society for Clinical Densitometry Position Development Conference on Bone Densitometry, J. Clin. Densitom., 16, 455-466, doi:10.1016/j.jocd.2013.08.004, 2013.

Serao, N. V., Veroneze, R., Ribeiro, A. M., Verardo, L. L., Braccini Neto, J., Gasparino, E., Campos, C. F., Lopes, P. S., and Guimaraes, S. E.: Candidate gene expression and intramuscular fat content in pigs, J. Anim. Breed. Genet., 128, 28-34, doi:10.1111/j.1439-0388.2010.00887.x, 2011.

Seto, E., Yoshida-Sugitani, R., Kobayashi, T., and ToyamaSorimachi, N.: The Assembly of EDC4 and Dcpla into Processing Bodies Is Critical for the Translational Regulation of IL-
6, PloS one, 10, e0123223, doi:10.1371/journal.pone.0123223, 2015.

Sornay-Rendu, E., Boutroy, S., Munoz, F., and Delmas, P. D.: Alterations of cortical and trabecular architecture are associated with fractures in postmenopausal women, independently of decreased bmd, The OFELY study, Osteoporosis Int., 17, S97-S97, 2006.

Soroko, S. B., Barrett-Connor, E., Edelstein, S. L., and KritzSilverstein, D.: Family history of osteoporosis and bone mineral density at the axial skeleton: the Rancho Bernardo Study, J. Bone Miner. Res., 9, 761-769, doi:10.1002/jbmr.5650090602, 1994.

Thomas, G., Betters, J. L., Lord, C. C., Brown, A. L., Marshall, S., Ferguson, D., Sawyer, J., Davis, M. A., Melchior, J. T., Blume, L. C., Howlett, A. C., Ivanova, P. T., Milne, S. B., Myers, D. S., Mrak, I., Leber, V., Heier, C., Taschler, U., Blankman, J. L., Cravatt, B. F., Lee, R. G., Crooke, R. M., Graham, M. J., Zimmermann, R., Brown, H. A., and Brown, J. M.: The serine hydrolase ABHD6 Is a critical regulator of the metabolic syndrome, Cell reports, 5, 508-520, doi:10.1016/j.celrep.2013.08.047, 2013.

Trammell, S. A. and Brenner, C.: NNMT: A Bad Actor in Fat Makes Good in Liver, Cell Metabolism, 22, 200-201, doi:10.1016/j.cmet.2015.07.017, 2015.

Ulrich, D., van Rietbergen, B., Laib, A., and Ruegsegger, P.: The ability of three-dimensional structural indices to reflect mechanical aspects of trabecular bone, Bone, 25, 55-60, 1999.

Valero, R., Bayes, M., Francisca Sanchez-Font, M., GonzalezAngulo, O., Gonzalez-Duarte, R., and Marfany, G.: Characterization of alternatively spliced products and tissue-specific isoforms of USP28 and USP25, Genome Biology 2001, 2, research0043.1-0043.10, 2001.

Vogl, T. J., Reith, W., and Rummeny, E. J.: Diagnostische und interventionelle Radiologie, Springer-Verlag Berlin Heidelberg, 2011.

Wei, T.: corrplot: Visualization of a correlation matrix, available at: http://CRAN.R-project.org/package=corrplot (last access: 13 February 2017), 2013.

Willing, M. C., Torner, J. C., Burns, T. L., Janz, K. F., Marshall, T., Gilmore, J., Deschenes, S. P., Warren, J. J., and Levy, S. M.: Gene polymorphisms, bone mineral density and bone mineral content in young children: the Iowa Bone Development Study, Osteoporosis international: a journal established as result of cooperation between the European Foundation for Osteoporosis and the National Osteoporosis Foundation of the USA, 14, 650-658, doi:10.1007/s00198-003-1416-1, 2003.

Wright, N. C., Looker, A. C., Saag, K. G., Curtis, J. R., Delzell, E. S., Randall, S., and Dawson-Hughes, B.: The recent prevalence of osteoporosis and low bone mass in the United States based on bone mineral density at the femoral neck or lumbar spine, J. Bone Miner. Res., 29, 2520-2526, doi:10.1002/jbmr.2269, 2014.

Xiao, S. M., Gao, Y., Cheung, C. L., Bow, C. H., Lau, K. S., Sham, P. C., Tan, K. C., and Kung, A. W.: Association of CDX1 binding site of periostin gene with bone mineral density and vertebral fracture risk, Osteoporosis international: a journal established as result of cooperation between the European Foundation for Osteoporosis and the National Osteoporosis Foundation of the USA, 23, 1877-1887, doi:10.1007/s00198-011-1861-1, 2012.

Yadav, A., Saini, V., and Arora, S.: MCP-1: chemoattractant with a role beyond immunity: a review, Clin. Chim. Acta, 411, 15701579, doi:10.1016/j.cca.2010.07.006, 2010. 
Yang, T. L., Guo, Y., Liu, Y. J., Shen, H., Liu, Y. Z., Lei, S. F., Li, J., Tian, Q., and Deng, H. W.: Genetic variants in the SOX6 gene are associated with bone mineral density in both Caucasian and Chinese populations, Osteoporosis international: a journal established as result of cooperation between the European Foundation for Osteoporosis and the National Osteoporosis Foundation of the USA, 23, 781-787, doi:10.1007/s00198-011-1626-x, 2012.

Yu, E. W., Thomas, B. J., Brown, J. K., and Finkelstein, J. S.: Simulated increases in body fat and errors in bone mineral density measurements by DXA and QCT, J. Bone Miner. Res., 27, 119124, doi:10.1002/jbmr.506, 2012.
Zhao, L. J., Jiang, H., Papasian, C. J., Maulik, D., Drees, B., Hamilton, J., and Deng, H. W.: Correlation of obesity and osteoporosis: Effect of fat mass on the determination of osteoporosis, J. Bone Miner. Res., 23, 17-29, doi:10.1359/Jbmr.070813, 2008.

Zhu, J., Shimizu, E., Zhang, X., Partridge, N. C., and Qin, L.: EGFR signaling suppresses osteoblast differentiation and inhibits expression of master osteoblastic transcription factors Runx2 and Osterix, J. Cell. Biochem., 112, 1749-1760, doi:10.1002/jcb.23094, 2011. 